\title{
REIC/Dkk-3 as a potential gene therapeutic agent against human testicular cancer
}

\author{
RYUTA TANIMOTO ${ }^{1}$, FERNANDO ABARZUA ${ }^{1}$, MASAKIYO SAKAGUCHI ${ }^{2}$, \\ MIKIRO TAKAISHI $^{2}$, YASUTOMO NASU ${ }^{1}$, HIROMI KUMON $^{1}$ and NAM-HO HUH ${ }^{2}$ \\ Departments of ${ }^{1}$ Urology and ${ }^{2}$ Cell Biology, Okayama University Graduate School of Medicine, \\ Dentistry and Pharmaceutical Sciences, Shikata-chou, Okayama 700-8558, Japan
}

Received June 23, 2006; Accepted August 29, 2006

\begin{abstract}
Human testicular cancer is very sensitive to chemotherapy and radiation therapy and is regarded as a curable cancer. The cancer prevails in the young reproductive generation and testicular dysfunction is often observed as a side effect, remaining a serious challenge. In the present study, we examined the potential utility of REIC/Dkk-3-based gene therapy against human testicular cancer. Expression of REIC/Dkk-3 was reduced in all of the human seminoma and non-seminomatous germ cell tumor tissues. Overexpression of REIC/Dkk-3 using an adenovirus vector (Ad-REIC) induced apoptosis in a testicular germ cell cancer cell line NCCIT but not in normal human fibroblasts. c-Jun terminal kinase (JNK) was activated by Ad-REIC and the induction of apoptosis was abrogated by a JNK inhibitor. A single intratumoral injection of Ad-REIC markedly inhibited the tumorigenic growth of NCCIT cells in nude mice. These results indicate that AdREIC may lead to developing less insulting and non-genotoxic therapeutic measures against human testicular cancer.
\end{abstract}

\section{Introduction}

Testicular cancer is the most common malignant disease occurring in young adult men. Although the incidence of testicular cancer in the general population is not remarkably high, it has been steadily increasing in recent decades (1). The majority of testicular cancer, i.e., 90 95\%, derives from germinal cells and is broadly classified as seminoma and non-seminomatous germ cell tumors (NSGCTs) (2). Testicular germ cell cancer is known to be highly sensitive to chemotherapy and radiation therapy. The rate of complete cure for patients with germ cell cancer is higher than $90 \%$ and nearly

Correspondence to: Dr N. Huh, Department of Cell Biology, Okayama University Graduate School of Medicine, Dentistry, and Pharmaceutical Sciences, 2-5-1 Shikata-cho, Okayama 700-8558, Japan

E-mail: namu@md.okayama-u.ac.jp

Key words: REIC, Dkk-3, testicular tumor, NCCIT, therapy all cases can be cured when at lower stages of tumor progression (3). Chemotherapy and radiation therapy, however, often result in unfavorable complications, including testicular dysfunction and infertility (4-6), secondary malignancies (7-9) and, less seriously, renal dysfunction and hearing disturbance (10). Oligospermia or aspermia is usually transient and many cured patients father children (11). Considering the young age of most patients, however, the forced interruption of conception attempts and possible necessity of reproductive assistance using cryo-preserved semen should not be overlooked. Less insulting and non-genotoxic therapeutic measures are certainly preferable for cancers arising in the gonadal organ.

REIC/Dkk-3 was originally isolated as a gene whose expression was reduced in immortalized human fibroblasts compared with that in normal counterparts (12), and subsequent analyses revealed that it is a candidate tumor suppressor gene (13). Expression of the REIC/Dkk-3 gene was reduced in many human cancer cells and tissues including prostate cancer, renal clear cell carcinoma, and non-small cell lung cancer (14-16). Forced expression of REIC/Dkk-3 using an adenovirus vector selectively induced apoptotic cell death in human prostate cancer cell lines with marginal effect in normal epithelial and stroma cells of prostate (16). The apoptosis involved JNK activation, mitochondrial translocation of Bax, and reduction of Bcl-2. In an animal model where human prostate cancer cells were subcutaneously transplanted in nude mice, a single injection of the adenovirus vector carrying REIC/Dkk-3 showed remarkable therapeutic effect, i.e., complete regression of the tumor in 4 of the 5 animals transplanted (16). Adenovirus vector is known to be hardly integrated into genomic DNA and thus non-genotoxic $(17,18)$. These results indicate the possible utility of REIC/Dkk3 as a selective non-genotoxic therapeutic measure. In the present study, therefore, we examined the expression of REIC/Dkk-3 in testicular cancers and the possible therapeutic effect of the overexpression of REIC/Dkk-3 on human testicular cancer cells.

\section{Materials and methods}

Tissues, cells and reagents. A testicular carcinoma tissue microarray was purchased from Folio Biosciences (Columbus, $\mathrm{OH})$. Surgically resected testicular cancer tissues were fixed with $4 \%$ paraformaldehyde and tissue sections were made under conventional conditions. NCCIT, a cell line established 


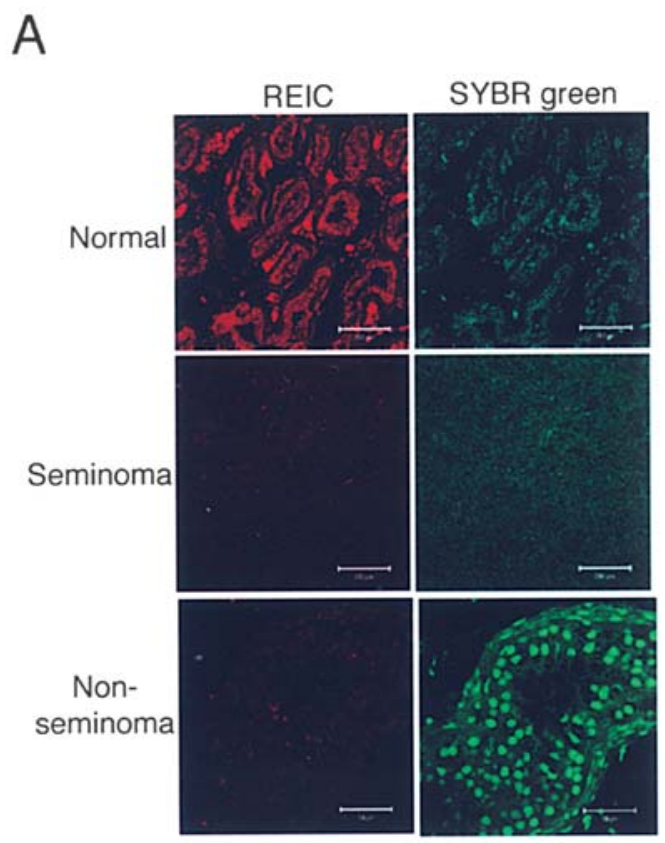

B

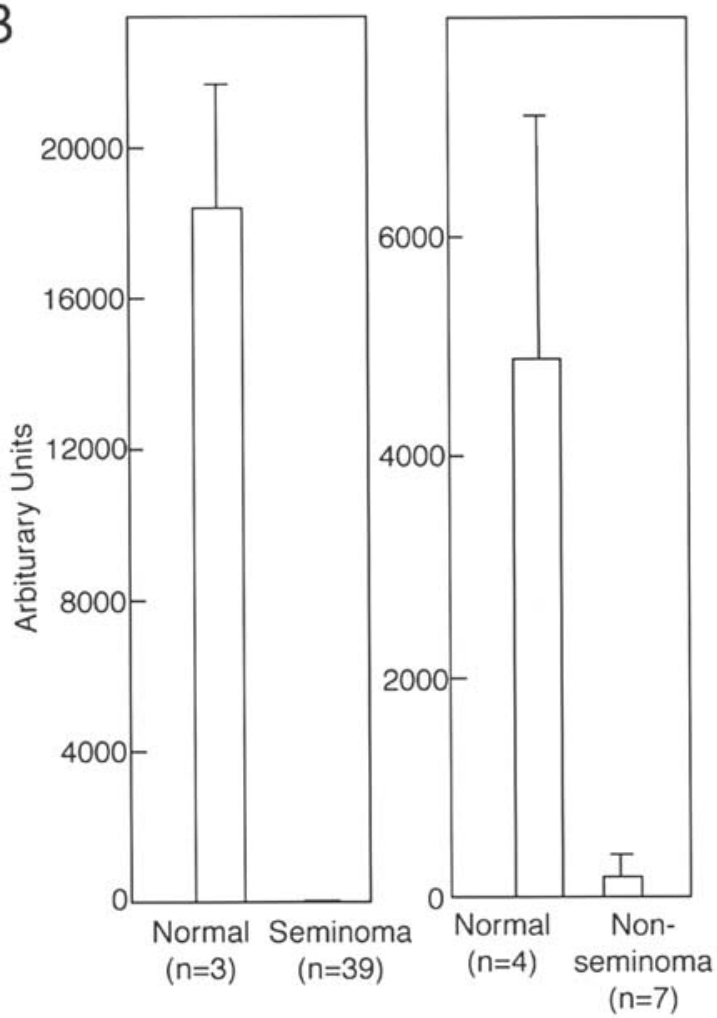

Figure 1. Expression of REIC/Dkk-3 in human seminoma and non-seminoma tissues. (A) Immunohistochemistry for REIC/Dkk-3 in representative normal testis and seminoma and non-seminoma tissues (red). Nuclei were visualized by staining with SYBR-Green. Scale bars; $200 \mu \mathrm{m}$ for normal and seminoma tissues, $50 \mu \mathrm{m}$ for non-seminoma tissue. (B) Quantitation of signals obtained by immunohistochemistry for REIC/Dkk-3. $\mathrm{n}$, number of tissues analyzed; ordinate, arbitrary units; vertical bars, standard deviation.

from mixed germ cell tumor, was purchased from ATCC and maintained in RPMI-1640 supplemented with $10 \%$ fetal bovine serum. A c-Jun N-terminal kinase (JNK) inhibitor SP600125 was purchased from BioMol (Plymouth Meeting, PA).

Immunohistochemistry. Tissue sections and microarrays were immunostained with anti-human REIC/Dkk-3 antibody raised in our laboratory, followed by treatment with Alexa fluor R594-conjugated goat anti-rabbit IgG antibody (Molecular Probes, Eugene, OR). Vectashield mounting medium with DAPI (Vector Laboratories, Burlingame, CA) was used for counter-staining of cell nuclei. SYBR-Green I (Cambrex) was used for nuclear staining in tissue sections. The signal intensity of the stained samples was quantitated using the computer software Scion Image Beta (Scion, Frederick, ML).

$R T-P C R$. RT-PCR was performed under the conditions recommended by the manufacturer using a LightCycler ${ }^{\mathrm{TM}}$ rapid thermal cycler instrument (Roche Diagnostic, Lewes, UK). The primers used were as follows: REIC/Dkk-3 (forward) 5'GTAAGTTCCCCTCTGGCTTG-3', REIC/Dkk-3 (reverse) 5'-AAGCACCAGACTGTGAAGCCT-3'; GAPDH (forward) 5'-GGGTGTGAACCATGAGAAGTATGA-3', GAPDH (reverse) 5'-TGCTAAGCAGTTGGTGGTGC-3'. The products were identified by a melting point analysis, electrophoretic mobility, and direct sequencing. Standard curves for calculation of the number of transcripts were made using plasmid containing the respective inserts. The results are shown as molar ratios of REIC/Dkk-3 to GAPDH transcripts
Western blot analysis. Western blot analysis was performed using protein extracts prepared at $48 \mathrm{~h}$ after infection of the adenovirus vectors. The antibodies used were as follows: rabbit anti-human REIC/Dkk-3 antibodies raised in our laboratory for REIC/Dkk-3; apoptosis sampler I kit (BD Biosciences, San Jose CA) for Bcl-2 and Bcl-xL; rabbit anti-human Bax antibody (Upstate Cell Signaling Solutions); mouse anti-horse cytochrome c antibody (Upstate Biotechnology, Lake Placid, NY); rabbit anti-human c-Jun antibody, rabbit anti-human phospho-c-Jun (Ser63) antibody, rabbit anti-human SAPK/JNK antibody, and rabbit anti-human phospho-SAPK/JNK (Thr183/ Tyr185) antibody (Cell Signaling Technology, Beverly, MA); and mouse anti-human $\beta$-actin antibody (Sigma, St. Louis, $\mathrm{MO})$.

Overexpression of REIC/Dkk-3 and monitoring of apoptotic cells. REIC/Dkk-3 was overexpressed by infecting cells with an adenovirus vector carrying REIC/Dkk-3 (Ad-REIC) described previously (16). A vector carrying LacZ (Ad-LacZ) was used as a negative control. Seventy-two hours after infection of the virus vectors at $20 \mathrm{MOI}$, apoptotic cells were monitored by TUNEL method using an in situ cell death detection kit (Roche).

In vivo experiments. NCCIT cells $\left(3.0 \times 10^{6}\right.$ in $\left.50 \mu 1 \mathrm{PBS}\right)$ were mixed with $50 \mu 1$ Matrigel (BD Biosciences) and subcutaneously injected into the right flank of 8-week-old BALB/C nude mice (SLC, Hamamatsu, Japan). Three weeks after injection, when the tumor diameter reached $\sim 5 \mathrm{~mm}$, 
$2.0 \times 10^{8}$ pfu of Ad-REIC or Ad-LacZ in a $100 \mu 1$ buffer were injected intratumorally. The size of the tumors was measured every 3 or 4 days for 30 days after the injection. Tumor volume was calculated using an empirical formula, $\mathrm{V}=1 / 2 \mathrm{x}$ (the shortest diameter) $2 \mathrm{x}$ (the longest diameter).

\section{Results and Discussion}

Reduced expression of REIC/Dkk-3 in testicular tumor tissues. We first examined the expression of the REIC/Dkk-3 gene in testicular tumor tissues. Immunostaining for REIC/Dkk-3 of a tissue microarray carrying 3 normal testicular tissues and 39 seminoma tissues showed that none of the seminoma tissues gave rise to any detectable signals while all the normal tissues were definitely positive for the expression (Fig. 1A). For non-seminoma cancer cases, clinically resected tissue samples were analyzed. All the non-seminoma tissues were negative in expression of REIC/Dkk-3. Quantitation of the signal intensity by computer software confirmed negative expression of REIC/Dkk-3 in both types of testicular cancer (Fig. 1B).

At present, the molecular mechanism of the reduced expression of REIC/Dkk-3 is not completely clear, although
A

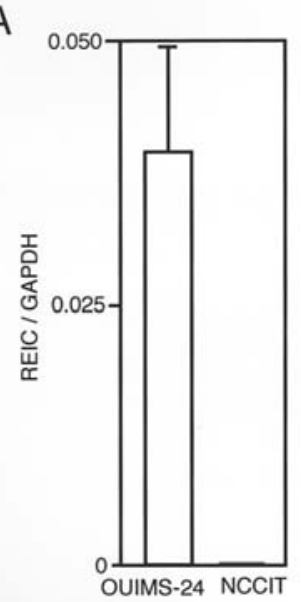

B

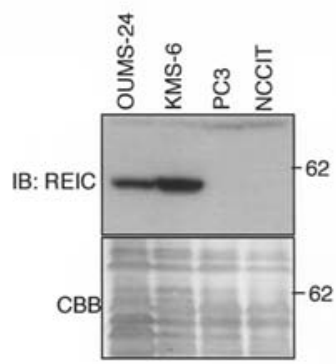

Figure 2. Reduced expression of REIC/Dkk-3 in a malignant human testicular germ cell cancer line, NCCIT. (A) Quantitative RT-PCR for REIC/Dkk-3 mRNA in normal human fibroblasts (OUMS-24) and NCCIT. Results were shown as molar ratios of REIC/Dkk-3 mRNA to GAPDH mRNA. (B) Western blot analysis for REIC/Dkk-3 protein in the designated cells. Normal human fibroblasts (OUMS-24 and KMS-6) and a human prostate cancer cell line (PC3) were used as positive and negative controls, respectively. $\mathrm{CBB}$, stained with Coomassie Brilliant Blue.

A

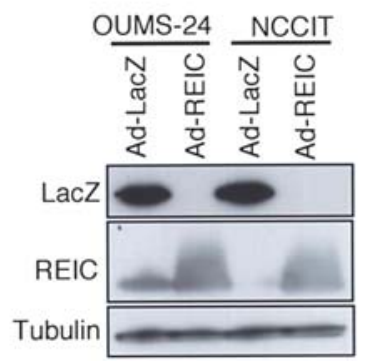

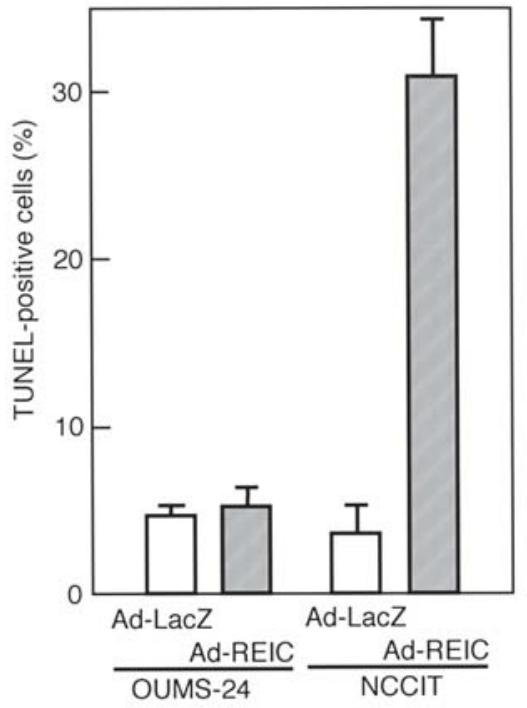

B

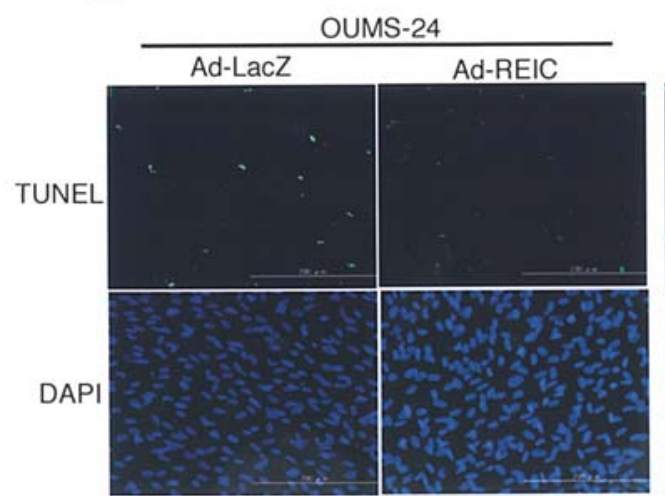

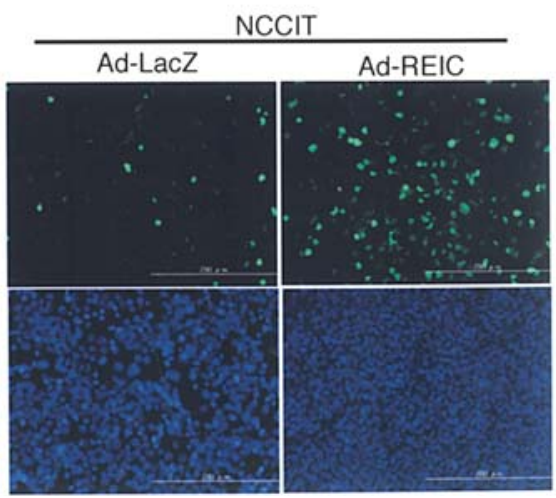

Figure 3. Induction of apoptotic cell death of NCCIT cells by overexpression of REIC/Dkk-3. (A) Overexpression of REIC/Dkk-3 or LacZ by an adenovirus vector. Cells were harvested $72 \mathrm{~h}$ after infection at $20 \mathrm{MOI}$ for Western blot analysis. Tubulin was used as a control for applied amounts of protein. (B) TUNEL staining of cells $72 \mathrm{~h}$ after infection of the vectors at 20 MOI. Nuclei were visualized by DAPI staining. Scale bars, $200 \mu \mathrm{m}$. (C) Quantitation of the TUNEL-positive cells shown in B. Vertical bars, standard deviation. 
A

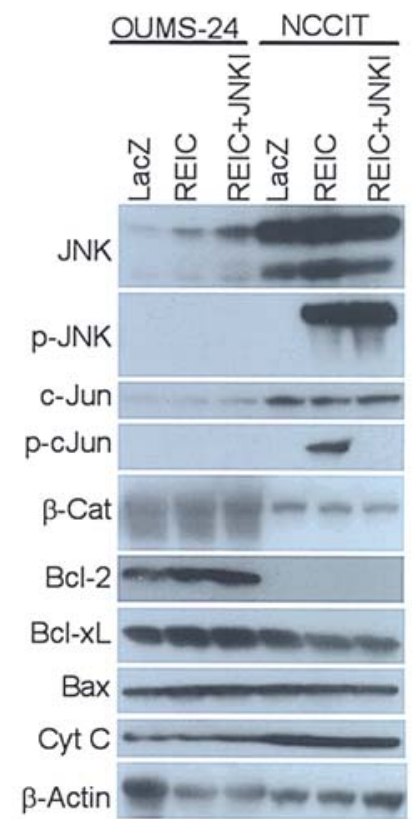

C

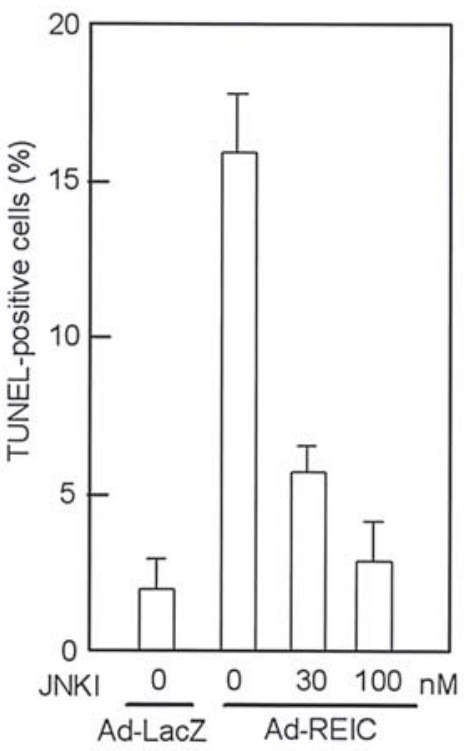

B

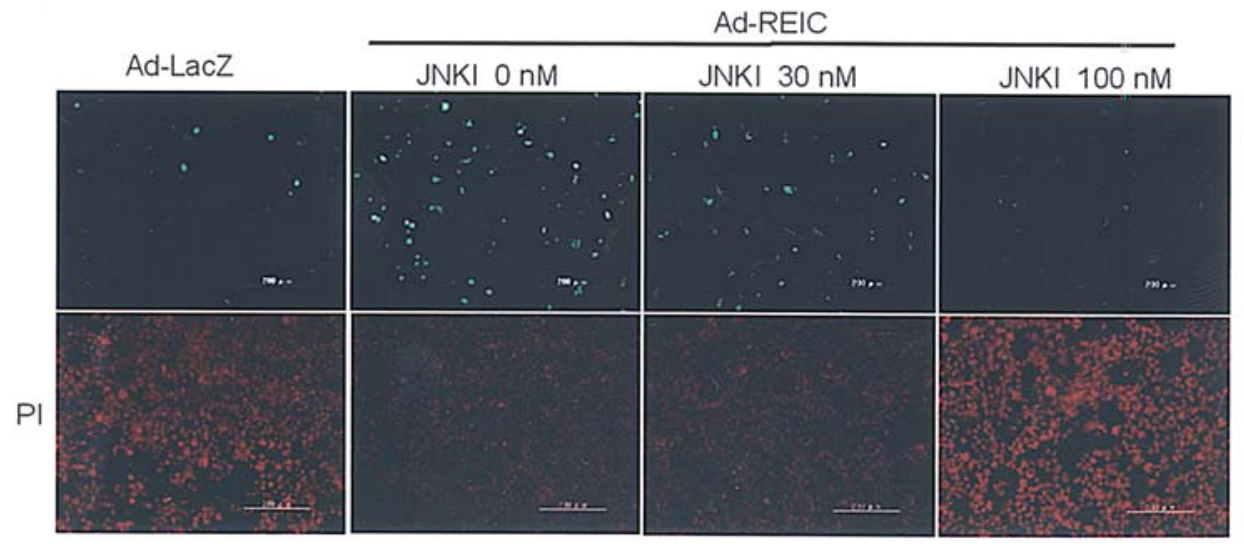

Figure 4. Abrogation of REIC/Dkk-3-induced apoptosis by JNK inhibitor. (A) Western blot analysis for designated proteins of NCCIT cells treated under the same conditions as those in B. The concentration of SP600125 was $100 \mathrm{nM}$. p-, phosphorylated; $\beta$-Cat, B-catenin; Cyt C, cytochrome C. (B) NCCIT cells were infected with Ad-LacZ or Ad-REIC at 20 MOI. JNK inhibitor SP600125 was added $1 \mathrm{~h}$ after the infection and the cells were fixed for immunostaining. PI, nuclear staining with propiodium iodide. (C) Quantitation of TUNEL-positive cells shown in A. Vertical bars, standard deviation.

hypermethylation of the REIC/Dkk-3 promoter was indicated to be at least partly involved (19). In our previous study, we noted some discrepancy between the expression level of REIC/Dkk-3 in terms of mRNA and that of protein, i.e., REIC/Dkk-3 protein was null in some cancer cases in which REIC/Dkk-3 mRNA was detected (15). This means that we should determine the protein levels of REIC/Dkk-3 for functionally relevant comparison among different cell types. Significant decrease in REIC/Dkk-3 protein was observed in 6 of the 7 and 13 of the 14 renal clear cell carcinoma cases analyzed by Western blotting and immunohistochemistry, respectively (15). For prostate cancer, twelve cases analyzed in a microarray and 40 cases analyzed in clinically resected tissues showed reduced expression of REIC/Dkk-3 protein depending on Gleason scores (16). Together with the results of the present study, it is now clear that the REIC/Dkk-3 protein level consistently decreased in most of the cases in 3 representative types of urogenital cancer.
Lack of REIC/Dkk-3 expression in NCCIT cells. For further studies on relevance of REIC/Dkk-3 to human testicular cancers, we chose a cell line derived from non-seminomatous germ cell tumor, NCCIT, since the cell line shows hybrid features of seminoma and embryonal carcinoma and can differentiate into various cell types of three embryonic germ layers (20). At first, we examined the expression of REIC/ Dkk-3 in NCCIT cells. Quantitative RT-PCR revealed that the REIC/Dkk-3 mRNA level in NCCIT cells was negligible when compared with that in normal human fibroblasts OUMS-24 (Fig. 2A). No REIC/Dkk-3 protein was detected in NCCIT cells by Western blot analysis (Fig. 2B). In accordance with our previous study (16), the protein was detected in normal human fibroblasts as a band of $\sim 62 \mathrm{kDa}$ but not in prostate cancer cell line PC3, which were used as a positive and negative control, respectively. Thus, NCCIT cells share the property lacking REIC/Dkk-3 expression with most testicular tumors and therefore were used for further studies. 


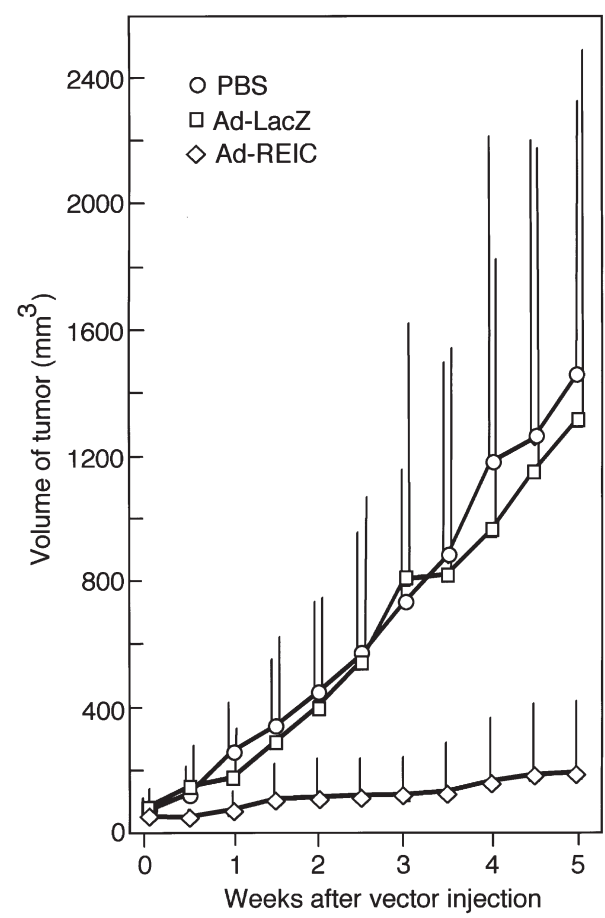

Figure 5. Suppression of the growth of NCCIT cells by Ad-REIC. Three weeks after subcutaneous transplantation of $3 \times 10^{7}$ NCCIT cells into nude mice, the adenovirus vectors $\left(2 \times 10^{8} \mathrm{pfu}\right)$ were injected once into the tumors. Vertical bars, standard deviation of tumor volume in 5 (Ad-REIC) or 6 (PBS or Ad-LacZ) mice.

Induction of apoptosis in NCCIT cells by overexpression of REIC/Dkk-3. Since our previous study showed that overexpression of REIC/Dkk-3 induced apoptosis in prostate cancer cell lines deficient in expression of the gene, we examined its effect on NCCIT cells. Infection of a replicationdeficient adenovirus vector carrying either LacZ (Ad-LacZ) or REIC/Dkk-3 (Ad-REIC) to OUMS-24 and NCCIT cells at $20 \mathrm{MOI}$ resulted in overexpression of the proteins at comparable levels (Fig. 3A). Under these conditions, infection efficiency was nearly $100 \%$ in both cell types (data not shown). When the apoptotic event was monitored by TUNEL staining $72 \mathrm{~h}$ after infection, $31 \%$ of NCCIT cells were positive after infection with Ad-REIC. OUMS-24 cells exhibited the positive signal in only $5.3 \%$ of the cells infected with Ad-REIC, the rate being comparable to those obtained after Ad-LacZ infection (Fig. 3B and C). These results indicate that overexpression of REIC/Dkk-3 selectively induces apoptotic cell death in NCCIT cells in a similar manner for prostate cancer cell lines as reported previously (16). In the present study, however, direct comparison of NCCIT cells and their normal counterparts was hampered by unavailability of the latter. Although mechanisms underlying the preferential induction of apoptosis in NCCIT cells remain to be clarified, our ongoing study indicates that the functional state of proteins involved in stress-induced apoptosis plays some roles. In this respect, it is noteworthy that the protein level of proapoptotic JNK was higher and that of anti-apoptotic Bcl-2 was lower in NCCIT cells than in the respective counterpart OUMU-24 (Fig. 4A). $A d-R E I C$. Since our previous study using a prostate cancer cell line indicated the involvement of c-Jun terminal kinase (JNK) in the induction of apoptosis by Ad-REIC, we examined the protein levels and phosphorylation state of JNK and other apoptosis-related proteins by Western blot analysis. As shown in Fig. 4A, infection of Ad-REIC resulted in phosphorylation and activation of JNK in NCCIT cells but not in OUMS-24. The activation of JNK was demonstrated by phosphorylation of the substrate protein c-Jun. Application of an inhibitor of JNK, SP600125, at $100 \mathrm{nM}$ completely abrogated phosphorylation of c-Jun. SP600125 is known to inhibit the activity of JNK1, JNK2, and JNK3 but not their autophosphorylation (21).

To see whether activation of JNK is causally linked to the induction of apoptosis, we examined the effect of SP600126 on Ad-REIC-induced apoptosis. As shown in Fig. 4B and C, addition of SP600126 dose-dependently abrogated apoptotic cell death in NCCIT cells exposed to Ad-REIC, indicating that activation of JNK is essential to the apoptosis-inducing function of Ad-REIC.

Inhibition of tumorigenic growth of NCCIT in nude mice by Ad-REIC. Finally, we investigated the effect of Ad-REIC on the growth of NCCIT cells in vivo as a possible therapeutic model. NCCIT cells of $3 \times 10^{6}$ were subcutaneously transplanted into nude mice and 3 weeks later $2 \times 10^{8}$ pfu of Ad-REIC or Ad-LacZ in $100 \mathrm{ml}$ was injected intratumorally. In control animals which received PBS or Ad-LacZ, the tumors grew progressively to reach $\sim 1,200 \mathrm{~mm}^{3}$ in size at the end of the observation period of 5 weeks (Fig. 5). In contrast, the tumor completely disappeared in 2 of the 5 mice injected with Ad-REIC and the mean tumor size among the 5 mice remained largely unchanged.

Concluding remarks. In the present study, we examined the potential utility of REIC/Dkk-3 as a gene-therapeutic agent against testicular cancer. Expression of REIC/Dkk-3 was reduced in all of the human seminoma and NSGCT tissues examined. Adenovirus-mediated overexpression of REIC/ Dkk-3 preferentially induced apoptotic cell death in a testicular germ cell carcinoma cell line, NCCIT, defective in expression of REIC/Dkk3. Furthermore, intratumoral injection of the adenovirus vector carrying REIC/Dkk-3 remarkably suppressed tumorigenic growth of NCCIT cells subcutaneously transplanted into nude mice. These results indicate that adenovirusmediated overexpression of REIC/Dkk-3 may be a promising approach for developing more patient-friendly therapeutic measures against human testicular cancer.

\section{Acknowledgments}

Scientific Research grant from the Japan Society for the Promotion of Science [B(2) 15390491; Y. Nasu], Health and Labor Sciences Research Grant from the Ministry of Health, Labor and Welfare (Third Term Comprehensive Control Research for Cancer; H. Kumon), and a grant from the Okayama Prefecture Industrial Promotion Foundation (N. Huh). We would like to thank Ms. Yuka Matono and Mr. Katsuo Ohno for their technical assistance.

\section{References}

1. Huyghe E, Matsuda T and Thonneau P: Increasing incidence of testicular cancer worldwide: a review. J Urol 170: 5-11, 2003. 
2. Rosai J: Male reproductive system. In: Surgical Pathology. Rosai and Ackerman (eds). 9th edition, Mosby-Elsevier Inc., New York, pp1417-1436, 2004.

3. Dearnaley D, Huddart R and Horwich A: Regular review: Managing testicular cancer. Br Med J 322: 1583-1588, 2001.

4. Drasga RE, Einhorn LH, Williams SD, Patel DN and Stevens EE: Fertility after chemotherapy for testicular cancer. J Clin Oncol 1: 179-183, 1983.

5. Hansen PV, Trykker H, Helkjoer PE and Andersen J: Testicular function in patients with testicular cancer treated with orchiectomy alone or orchiectomy plus cisplatin-based chemotherapy. J Natl Cancer Inst 81: 1246-1250, 1989.

6. Stephenson WT, Poirier SM, Rubin L and Einhorn LH: Evaluation of reproductive capacity in germ cell tumor patients following treatment with cisplatin, etoposide, and bleomycin. J Clin Oncol 13: 2278-2280, 1995

7. Pedersen-Bjergaard J, Daugaard G, Hansen SW, Philip P, Larsen SO and Rorth M: Increased risk of myelodysplasia and leukaemia after etoposide, cisplatin, and bleomycin for germ-cell tumours. Lancet 338: 359-363, 1991.

8. Travis LB, Curtis RE, Storm H, Hall P, Holowaty E, Van Leeuwen FE, Kohler BA, Pukkala E, Lynch CF, Andersson M, Bergfeldt K, Clarke EA, Wiklund T, Stoter G, Gospodarowicz M, Sturgeon J, Fraumeni JF Jr and Boice JD Jr: Risk of second malignant neoplasms among long-term survivors of testicular cancer. J Natl Cancer Inst 89: 1429-1439, 1997.

9. Travis LB, Andersson M, Gospodarowicz M, van Leeuwen FE, Bergfeldt K, Lynch CF, Curtis RE, Kohler BA, Wiklund T, Storm H, Holowaty E, Hall P, Pukkala E, Sleijfer DT, Clarke EA, Boice JD Jr, Stovall M and Gilbert E: Treatment-associated leukemia following testicular cancer. J Natl Cancer Inst 92: 1165-1171, 2000.

10. Osanto S, Bukman A, Van Hoek F, Sterk PJ, De Laat JA and Hermans J: Long-term effects of chemotherapy in patients with testicular cancer. J Clin Oncol 10: 574-579, 1992.

11. Brydoy M, Fossa SD, Klepp O, Bremnes RM, Wist EA, Wentzel-Larsen T and Dahl O: Paternity following treatment for testicular cancer. J Natl Cancer Inst 97: 1580-1588, 2005.
12. Tsuji T, Miyazaki M, Sakaguchi M, Inoue Y and Namba M: A REIC gene shows down-regulation in human immortalized cells and human tumor-derived cell lines. Biochem Biophys Res Commun 268: 20-24, 2000

13. Tsuji T, Nozaki I, Miyazaki M, Sakaguchi M, Pu H, Hamazaki Y, Iijima $\mathrm{O}$ and Namba M: Antiproliferative activity of REIC/Dkk-3 and its significant down-regulation in non-small-cell lung carcinomas. Biochem Biophys Res Commun 289: 257-263, 2001.

14. Nozaki I, Tsuji T, Iijima O, Ohmura Y, Andou A, Miyazaki M, Shimizu N and Namba M: Reduced expression of REIC/Dkk-3 gene in non-small cell lung cancer. Int J Oncol 19: 117-121, 2001.

15. Kurose K, Sakaguchi M, Nasu Y, Ebara S, Kaku H, Kariyama R, Arao Y, Miyazaki M, Tsushima T, Namba M, Kumon H and Huh NH: Decreased expression of REIC/Dkk-3 in human renal clear cell carcinoma. J Urol 171: 1314-1318, 2004.

16. Abarzua F, Sakaguchi M, Takaishi M, Nasu Y, Kurose K, Ebara S, Miyazaki M, Namba M, Kumon $\mathrm{H}$ and Huh NH: Adenovirusmediated overexpression of REIC/Dkk-3 selectively induces apoptosis in human prostate cancer cells through activation of cJun-NH2-kinase. Cancer Res 65: 9617-9622, 2005.

17. Zabner J, Petersen DM, Puga AP, Graham SM, Couture LA, Keyes LD, Lukason MJ, St George JA, Gregory RJ, Smith AE, et al: Safety and efficacy of repetitive adenovirus-mediated transfer of CFTR cDNA to airway epithelia of primates and cotton rats. Nat Genet 6: 75-83, 1994.

18. Brody SL and Crystal RG: Adenovirus-mediated in vivo gene transfer. Ann NY Acad Sci 716: 90-103, 1994.

19. Kobayashi K, Ouchida M, Tsuji T, Hanafusa H, Miyazaki M, Namba M, Shimizu N and Shimizu K: Reduced expression of the REIC/Dkk-3 gene by promoter-hypermethylation in human tumor cells. Gene 282: 151-158, 2002.

20. Damjanov I, Horvat B and Gibas Z: Retinoic acid-induced differentiation of the developmentally pluripotent human germ cell tumor-derived cell line, NCCIT. Lab Invest 68: 220-232, 1993.

21. Bennett BL, Sasaki DT, Murray BW, O'Leary EC, Sakata ST, $\mathrm{Xu}$ W, Leisten JC, Motiwala A, Pierce S, Satoh Y, Bhagwat SS, Manning AM and Anderson DW: SP600125, an anthrapyrazolone inhibitor of Jun N-terminal kinase. Proc Natl Acad Sci USA 98: 13681-13686, 2001. 